\title{
Surgical treatment of congenital heart conditions: It's now or never!
}

\author{
Rajesh Sharma ${ }^{1}$ \\ Received: 28 December 2020 / Accepted: 4 January 2021 / Published online: 28 January 2021 \\ (C) Indian Association of Cardiovascular-Thoracic Surgeons 2021
}

Pediatric cardiac surgeons from the fraternity were invited to pen down their learning and insight on topics of their interest. We did not want pedagogical write-ups, but essential material of practical use. To those of us having difficulty getting off the blocks, our advice was: Just write down the essentials on the topic that you can think of, what guidelines you use in your practice, your experience with these groups of patients, and your opinion of the future of care of this condition. And then build around all these points.

The contributions have been compiled in this issue, and hopefully in another to follow. Because congenital heart conditions are as myriad as the fish in the sea, and, for those dealing with them day in and day out, the collected data so invaluable and diverse, one, or even 2 issues, will not suffice. This first special issue is therefore a compilation of topical reviews, thoughts, and personal experiences of the contributors on various topics of contemporary importance. Of note, all the contributors are from India, where they attained part or all of their training in cardiac surgery, though some are currently located abroad. From the borderline left ventricle to atrioventricular canal to the anatomic repair of abnormal great arterial connections using the recent techniques of root transfers, to coronary interventions in children, the topics cover a wide range.

The opening chapter tracing the beginnings of cardiac surgery in India is a landmark contribution, I feel. Because that is when the DNA of our profession, its work ethic, was laid down. To date, it serves as inspiration for us to emulate. The origins of cardiac surgery in India can be traced back to the inspiring and hard work of the pioneers in the 1960s. These times were fairly contemporary with the birth of open intracardiac repair in the world. Making the indigenous heart lung

Rajesh Sharma

rsharmacvs@hotmail.com

1 Department of Pediatric Cardiac Surgery, Apollo Indraprastha Hospital, Sarita Vihar, Mathura Road, New Delhi 110076, India machine in those times, a feat (sadly) un-replicated ever since, and popularizing its use in many centers of the country were stellar achievements indeed, in times when communication and travel were tedious. Those times and succeeding endeavors and accomplishments are captured by Dr. Krishna Manohar in the opening pages. We are indebted to him for treating this important topic seriously enough to take the time (and pleasure) to visit many of our heroes in their homes and hometowns, individually, for a personal interview. My request that his delivery be captured verbatim, without alteration, was generously acceded to by our honorable editor, and for that I am grateful.

Another dedication is about the availability and affordability of pediatric cardiac surgery all over the world - a grim reminder of the alarming state, children's health is in, in most of the world, even in the twenty-first century. India has the dubious distinction of being among those nations where, even though high-quality cardiac care is available, its scale is limited and its affordability beyond the reach of $98 \%$ of the children requiring intervention.

All in all, I hope the issue and the following one prove a precious contribution by our very own, for our very own, surgeons in different parts of the world who are in similar situations as us, and for posterity.

\section{Cardiac surgery in India. Trouble ahead. A proposed way forward and the central role for congenital cardiac surgery}

Cardiac surgery is one of the best professions that exist today. It is immensely satisfying and intellectually and technically challenging, yet learnable. It has great variety, gives immediate, and often long-lasting, benefit and prolongs or normalizes lifespans potentially shortened by natural histories of conditions.

In India, due to the numerical disproportion between population affected and cardiac surgeons available to treat it, the demand is great. So why is it that, today, we have so few 
young medical graduates and surgeons enrolling in the superspecialization programs, the Master of Chirurgiae (MCh) and Diplomate National Board (DNB)? This trend has persisted over 3 entrance tests and the numbers in 2019/2020 were particularly alarming - $135 / 165 \mathrm{MCh}$ seats and 17 of the 18 DNB seats went vacant.

This should send alarm bells ringing among the planners of medical education of the country and among us, the current fraternity of cardiothoracic surgeons. With a grossly unmet demand, we can ill afford a further shortfall of surgeons. The specter of patients once again going abroad for treatment, which used to happen when I was training and before we attained world standards and the existing surgical fraternity was even smaller, threatens to loom large in a few years when the current generation hangs up its boots. Since patients are limited in the West, training programs from there could be expected to make surgical safaris into the country, due to our massive unmet demand, for the purpose of training their own. Where will our prestige go if our patients start going to neighboring countries of the subcontinent for their treatment! And worst of all, where will the millions suffering from heart ailments requiring surgery go, who cannot afford the above? Health tourism, constituted currently of foreign patients coming to us for their surgery, which was being identified as the potential next economic boom, after the information technology (IT) revolution, will dry up.

The steps envisaged by the agencies in charge of medical postgraduate enrollment, so far, have been: (1) reduction of the admission percentile, and (2) doing away with the bond for serving in government hospitals in some states. The first will only dilute quality and the second measure may not suffice. The factors leading to the disillusionment in the young graduates for cardiac surgery need to be delved into carefully, if we hope to reverse the trend.

I would like to take the opportunity to share my thoughts:

1. The surgeons of the day, when cardiac surgery began in India, were indeed heroes of the time, no less than God for their patients and to their students - us. Open heart surgery was new, there was glamor in stopping the heart, fixing it and restarting it, and bringing patients back to life. Our Gods inspired a whole generation of aspiring surgeons and new centers in the major hospitals of the country. The cardiac surgeon, with his flamboyant style and dexterity with the needle holder, was the newly crowned king of surgeons. He sired a complete generation of surgeons, who followed without a thought for the earnings, just for the hope that they would be able to replicate his actions, to operate on the heart one day. Then came the next generation, and, with the presence and influence of the pioneers still fresh, the same DNA was transferred. Those were the halcyon days of busy industry, when one operated all day, lived in the intensive care unit
(ICU), went home for a change, and was back at 8 next morning, for the next day's list.

By the time I entered the specialty, after MCh and a couple of fellowships in 1991, cardiac surgery still ruled the roost among the surgical subspecialties. Due to limited hospitals and logistic requirements, centers were still limited and there were no more than 20 surgeons dealing with pediatric congenital heart conditions throughout the country. Today, the national pediatric cardiac surgical WhatsApp group itself has 150 members and another 50 non-members may be safely assumed. A ten times increase in the number of surgeons in a 30 -year period is no mean accomplishment. Yet, the requirement is many times higher.

Today, the student passing out of Class XII and considering a medical career sees multiple more lucrative options. His horizons are broader than were ours and he knows the salary and living standard discrepancies among doctors and non-doctors and doctors and cardiac surgeons, the government setup surgeons and surgeons in private hospital. In the age of the Internet, he does not go by silly hero worship. He has the numbers in front of him and, with all due respect, he can choose intelligently. In the earlier days, cardiac surgery was new enough for cardiac surgeons to be regarded as role models and heroes. At a time when science stream students took up either engineering or medicine, those medical students taking up cardiac surgery took the branch that was at the apex and really the royalty of the medical profession. At that time, there was no private healthcare in India, so salaries were low, but in those days the top students went for cardiac surgery for the glamor, the challenge, and the respect of society.

Here, it is pertinent to note that super-specializations like MCh gastroenterology surgery are still in demand. The remuneration for a gall bladder removal, or other general surgical procedures, is much higher than can be earned from a cardiac surgery, with lesser stakes. Noncardiac surgical procedures can be performed with lesser investment, and lesser infrastructure than training for cardiac surgery.

Traditionally in India, in the early days, cardiac surgery was limited to government hospitals. Private healthcare entered in the late 1980s. First adult, and then gradually, pediatric cardiac surgery entered into private hospitals. Government hospitals were always more affordable for the patient, and have always had their hands full. Waiting lists in them, going into years, have become routine. However, today, a good proportion of congenital heart disease (CHD) operations in the country are being conducted in private hospitals. Here, the surgical package that a patient need pay is, in general, three times the government hospital package and few domestic patients can 
afford out of pocket payment. In defense of the private hospitals, they need to account for overheads like staff salary, infrastructure, and other facilities, while government hospitals need only account for consumables and bed charges. The standards of surgery are high, the facilities are esthetic, and even families with limited means aspire to get their children operated in the private hospitals, despite the expense. To their credit, government and non-government organizations have stepped up and introduced many schemes and avenues to offer financial assistance towards payment of treatment packages. However, in spite of piecemeal contributions from different sources, a definite percentage of the families get pushed below the poverty line, trying to pay for their children's treatment from their pockets.

In 2020, even though many new centers have sprung up, the private and government hospitals catering to CHD surgery are concentrated in metropolitan cities, where there is resulting unhealthy competition among the private setups, for the limited patients who enter the city, window shopping for the lowest rates, while the rest of the country is teaming with untreated $\mathrm{CHD}$, secondary to shortage of money, and the lack of centers and skilled trained professionals. In the current situation, on some days in the same city, there may be a glut of patients vying for admission in the government hospitals, while the surgeon in the private hospital close by is twiddling his thumbs with an empty outpatient. In addition to Indian patients, private hospitals also cater to foreign patients and actually prefer them to locals, since, unlike the domestic patient, they can easily pay their packages (which are low compared to the health services being offered in Europe or other healthcare destinations in Southeast Asia). Health tourism, as it is called now, actually contributes substantially to the cash inflow in private hospitals.

Private hospitals have also served another important purpose. Since the remuneration of the senior staff here is much better than in the government counterparts, senior experienced surgeons in government hospitals get invited to join private hospitals. Private hospitals, therefore, are not only an aspiration for parents to get their children treated in but also for surgeons to migrate to for a better personal economic package.

2. The numbers of patients undergoing coronary artery bypass (CABG) surgery, the bread and butter of the adult cardiac surgeon, have gone down. The reason is competition from the less invasive coronary stent. Notwithstanding multiple trials demonstrating superiority of the internal mammary graft, in terms of patency and longevity, the stent industry has invented a new wordnon-inferiority! Faced with the option of sternotomy or even a small incision (minimally invasive coronary surgery), explained by the gatekeeper cardiologist doing the angiogram, the stent most often gets chosen over surgery (even by us - the surgeons - when we become the patient!). Early stent results are non-inferior and who knows about the long term! Faced with a painful sternotomy on one hand and a discharge from hospital, back to work in $48 \mathrm{~h}$ on the other, the decision making process is really a no-brainer!

Percutaneous valve insertion and Mitraclip have come up and could potentially eat into the classic valve surgeons' practice. What prevents more widespread use of these percutaneous valve options is their prohibitive expense. However, surgeons feel they are missing out, so the trend to train in percutaneous valves has been introduced by the Indian Association of Cardiovascular and Thoracic Surgeons (IACTS) for surgeons too.

Heart failure treatment with heart replacement technologies and heart transplantation is gaining popularity and has potential to attract young blood, but is limited by expense.

The major patient base the surgeon still has, in this era of dwindling CABG patients, is a plentiful supply of children with CHD. Cath lab treatment of CHD is limited to a few simple lesions, so a vast majority of remaining CHD patients still require surgical treatment, unlike the coronary artery disease (CAD) situation.

So far, congenital cardiac surgery has been the poor cousin to adult cardiac surgery in India. It was always the less glamorous, as it dealt with poor people, but is technically more challenging and time consuming. It is prone to the more frequent post-operative low cardiac output state, and has higher morbidity and mortality. If you were an adult surgeon, you were king, but a pediatric surgeon was always drawn down to terra firma ever so often, whenever he dared dream of flying.

So far, CHD surgery has not caught on due to financial deficit among the population and due to lesser popularity among the new MCh and DNB pass-outs. Finances were always less of a problem for CABG because the adult is the breadwinner for the family and therefore is more likely to get himself operated upon, he is also the decision maker in the family and so no wonder he will obtain the finances for his own surgery. He is also covered by health insurance. But the child is voiceless, replaceable, likely to require re-surgery, likely to exceed surgical package due to reasons like sepsis, etc., so neither the hospital nor the surgeon, who can do both adults and pediatrics, can be faulted in choosing the adult patient to operate upon. In India, given the long waiting list in government hospitals, the less than ideal conditions in many, and the steep cost of private hospitals, to be born with a heart condition is a curse and only the rich can afford to have their sick child benefit from the life-saving miracle of open heart surgery. Many children with CHD become inoperable or die waiting for their turn.

Advocacy is hardly there when it comes to CHD. One hears of cancer and human immune-deficiency virus (HIV), 
even cleft lip, but if there is something that kills, it is CHD and if there is something that cures (and magically) it is congenital heart surgery. It is indeed amazing that CHD has throughout fallen on the blind spot of the corporate world, and the celebrities, when it comes to sponsorship and promotional activities.

In the era of social media, when reports of miraculous achievements of cardiac surgeons should be in plethora, with reports of successful heart transplantation therapy, longlasting benefits of arterial conduits for coronary bypass grafting, the awe-inspiring results of multiple congenital lesions like transposition of great arteries (TGA), total anomalous pulmonary venous connection (TAPVC), tetralogy of Fallot (TOF), and other repairs, which completely change the natural history of the condition, it is indeed astonishing that there is a relative lack of awe-inspiring gods (read surgeons) walking the firmament today, influencing the young impressionable minds, than in the days when not even television existed!

With the above, it is quite clear that one of the factors leading to our current problem of inability to attract the youth to our fold is the result of scarcity of work opportunity, and that too of financially attractive ones. The government has plans of setting up multiple institutes along the lines of the All India Institute of Medical Sciences (AIIMS), New Delhi, but the issue of attractive remunerations will remain, unless there is a creation of multiple private units in tier II cities.

To incentivize private hospitals to set up pediatric cardiac surgery units in tier II cities, there needs to be a good supply of patients who are able to bear the private hospital packages. The government, on its part, has introduced several schemes that enable the common man to get operated. Schemes like Yashaswini of Karnataka, Arogyashree of Andhra Pradesh, and school health program of Gujarat are limited to their state of origin. Rashtriya Bal Swasthya Karyakram (RBSK) is countrywide, as is Ayushman Bharat. The payback to enrolling hospitals occurs at low to moderate rates, which are procedure specific. However, private hospitals are hesitant to sign up onto these schemes, as the payment is quite low, often inordinately delayed, and hardly enough to cover even basic procedural expenses, leave alone the overheads like employee salaries, air conditioning, etc. Private hospitals who enroll for these yojanas therefore cherry pick the cheaper, simpler conditions which they can operate without incurring losses, and the more complicated cases get left out.

The private hospitals cannot be blamed if they prefer foreign patients, as the latter can afford the required packages. However, foreign countries, from where foreign-governmentsponsored patients used to come from, are also discouraging their patients from going to other countries and prefer them being operated within their own countries. It is cheaper than sending contingents and the local talent also gets to learn from visiting teams, with the goal of future independent functioning. The private self-paying foreign patients will continue to travel, but they are a small number, with many hospitals competing for them. In this scenario, it therefore makes sense to source our own patients from within the country. But how to get them to pay corporate surgical packages? Government schemes do not pay enough and are no encouragement for a private group to set up new centers with cardiac surgical units in more tier II cities.

In this entire scenario, private health insurance is the elephant in the room, that is getting away scot-free, without any responsibilities or duties towards playing a role for CHD. Today, private medical insurance does not cover any congenital condition. "Preexisting condition" is the professed reason for excluding congenital defects from their purview. In a country with $41 \%$ of the population below 18 years of age, with $50 \%$ of the population below 25 years of age and $65 \%$ below 35 years of age, where 25 million babies are born every year and 70,000 per day, if you are not born perfect, and your parents not rich enough to get you treated in a private hospital, all you have access to is the long waiting list in a government hospital. Ironically, the ability to buy one's life, if one is born with a heart defect, is confined to those born to the rich.

Unless backed by insurance or adequately funded schemes, private hospitals see no incentive to set up new pediatric cardiac surgery units in tier II cities, where the paying capacity is low. What is required is a cash infusion into the private hospitals taking care of CHD. In a country like India, where the government can ill afford keeping aside $5 \%$ of its gross domestic product (GDP) towards the health budget, it is impractical to expect it to be the source of this cash flow. The only source from where this cash flow can arise is private insurance. The government, and the judiciary, would be well advised to finally come down hard on insurance companies and ensure that the age-old national shameful, immoral practice of not supporting children born with an abnormality comes to an end. In a country where only $2 \%$ of CHD get treated, creating exclusion categories is hardly the way forward. Rather, there should be an all-hands-on-deck approach, with insurance companies chipping in. The government of the day would be well advised to issue a whip through the Insurance Regulatory and Development Authority of India (IRDAI) to ensure participation by all insurance providers with a percentage of the profits being channeled back into healthcare. If not after 70 years, are we waiting for a 100 years to be over? Many heart defects do not kill immediately. They result in loss of working capacity, wasted non-productive manpower, and burdens on the family and from heart defects that were easily and completely treatable, if addressed in time.

Coverage of congenital defects is an inalienable right of every one born with a defect, including one who can pay the premium. Enrollment should be compulsory for every pregnancy and has to be at the level of first presentation, before antenatal checkup. Since CHDs are the expensive component, 
and non-cardiac defects much cheaper to handle, a 1:100 rate (which is the incidence of CHD) would easily give the insurance companies a profit. Agreed, the poor socio-economic strata may have trouble affording the premium, but the huge Indian middle class would fall under it. Since getting treated in private hospitals is so aspirational in India, improving socioeconomic strata, with some governmental assistance, would propel bigger numbers into the insurance, leading to setting up of newer units all over the country, in addition to the government hospitals like AIIMS that are in the government's plan. A higher number of paying patients would create space for government scheme-supported patients to be served too. These private units would pay surgeons better and would attract fresh talent for super-specialization. In other words, private insurance has to be persuaded, forced, or coerced into covering CHD, in tandem with a family/delivery policy. In a country where everyone gets married, and every marriage results in children, I am quite sure the companies have been ignoring this golden goose to their own detriment and they stand to gain immensely financially, given the very low incidence of CHD. For this, insurance has to take a leaf out of travel insurance.

Travel insurance has become a norm today for most air travel. In fact, many destination countries have made it a rule. This travel insurance also covers the period of stay for a certain period. The number of times it is used is rare, so it is a walk to the bank for the insurance companies, albeit not a big sum from each passenger. However, it does save the destination country from having to pay for treatment the huge cost of medical treatment, were it to be required.

Similarly, delivery insurance covering childbirth can be opted for at the time of taking insurance by women. Instead of rejecting birth defects on the artificial ground that they are pre-existent diseases (pray, what is not pre-existent for any newborn illness?), all that needs be done is to add birth defects to the delivery insurance at the time of registering. Congenital (cardiac and non-cardiac combined) defects occur with a frequency of $184 / 10,000$ live births or $2 / 100$, rounded off. Of these, about half (the noncardiac) require only inexpensive treatment, which will not hurt the insurance companies. Heart defects occur at 1/100 live births and these have the possibility of requiring expensive treatment with excellent results. Coverage of all pregnancies would easily cover for treatment of CHD, and leave a good profit for the insurance companies. There are downsides like need for multiple interventions, but the insurance can be designed in various innovative ways.

Today, the increasing rates of antenatal detection of simple congenital defects that are eminently treatable are temptation for a termination of pregnancy for the non-affording parents, if they have to shoulder the entire amount single-handedly and, often, what prevents that is detection of the abnormality too late to allow a termination. Imagine if a ventricular septal defect (VSD) was picked up at 20 weeks gestation and the couple opted for medical termination of pregnancy (MTP)!. Would our society be able to accept that with a clear conscience? This is not an exaggerated possibility. The onechild policy in China led to complete change in the demographics of CHD (tending to zero), where the facility of prenatal echo was available. That, if allowed to reach this stage, will surely be the death knell of cardiac surgery in our country.

The time to act is now. We have practiced our science and art long enough and concentrated on technical superiority and matching the best in the world, without giving serious thought to the poor patients of our own country, treating foreign patients because the heart is the same irrespective of origins, while actually allowing injustice to be meted out to our own. We individually, and through our associations, the IACTS, Pediatric Cardiac Society of India (PCSI), and the Society for Pediatric and Congenital Heart Surgeons (SPCHS), must press for the government and the judiciary to issue the required orders that insurance companies treat patients born with CHD, with the humanity they deserve, and not like orphans or lesser equals, as they have so far. If we, the caregivers, do not deliver what is due to the vast majority of patients of the country now, we will end up paying with the demise of our specialty. Even if this is hyperbole (and perhaps it is not), setting us and our society on the righteous track is a worthy goal. After all, we are only asking for the right of the child born with a heart defect to live. This may also well be our last chance to save cardiac surgery in our country. We owe the specialty that has given us so much, to press our just and fair demand with all the resource at our command.

One thing is very clear: If we can help our domestic patients survive, so will we.

May we and Indian Society take the correct moral decision that will bring the days of glory back to cardiothoracic vascular surgery in India and bring the country closer to the aim of timely treatment of heart diseases.

Happy reading.

Publisher's note Springer Nature remains neutral with regard to jurisdictional claims in published maps and institutional affiliations. 